\title{
Mapping malaria risk among children in Côte d'Ivoire using Bayesian geo-statistical models
}

\author{
Giovanna Raso ${ }^{1,2,3^{*}{ }^{+}}$, Nadine Schur ${ }^{2,3+}$, Jürg Utzinger ${ }^{2,3}$, Benjamin G Koudou ${ }^{1,4,5}$, Emile S Tchicaya ${ }^{1,6}$, Fabian Rohner ${ }^{7}$, \\ Eliézer K N'Goran ${ }^{1,6}$, Kigbafori D Silué ${ }^{1,6}$, Barbara Matthys ${ }^{3,8}$, Serge Assi ${ }^{9,10}$, Marcel Tanner ${ }^{2,3}$ \\ and Penelope Vounatsou ${ }^{2,3}$
}

\begin{abstract}
Background: In Côte d'Ivoire, an estimated 767,000 disability-adjusted life years are due to malaria, placing the country at position number 14 with regard to the global burden of malaria. Risk maps are important to guide control interventions, and hence, the aim of this study was to predict the geographical distribution of malaria infection risk in children aged $<16$ years in Côte d'Ivoire at high spatial resolution.
\end{abstract}

Methods: Using different data sources, a systematic review was carried out to compile and geo-reference survey data on Plasmodium spp. infection prevalence in Côte d'Ivoire, focusing on children aged $<16$ years. The period from 1988 to 2007 was covered. A suite of Bayesian geo-statistical logistic regression models was fitted to analyse malaria risk. Non-spatial models with and without exchangeable random effect parameters were compared to stationary and nonstationary spatial models. Non-stationarity was modelled assuming that the underlying spatial process is a mixture of separate stationary processes in each ecological zone. The best fitting model based on the deviance information criterion was used to predict Plasmodium spp. infection risk for entire Côte d'Ivoire, including uncertainty.

Results: Overall, 235 data points at 170 unique survey locations with malaria prevalence data for individuals aged $<16$ years were extracted. Most data points $(n=182,77.4 \%)$ were collected between 2000 and 2007. A Bayesian nonstationary regression model showed the best fit with annualized rainfall and maximum land surface temperature identified as significant environmental covariates. This model was used to predict malaria infection risk at non-sampled locations. High-risk areas were mainly found in the north-central and western area, while relatively low-risk areas were located in the north at the country border, in the north-east, in the south-east around Abidjan, and in the central-west between two high prevalence areas.

Conclusion: The malaria risk map at high spatial resolution gives an important overview of the geographical distribution of the disease in Côte d'Ivoire. It is a useful tool for the national malaria control programme and can be utilized for spatial targeting of control interventions and rational resource allocation.

\section{Background}

In 2004, Côte d'Ivoire was ranked at position number 14 with regard to the global burden of malaria with an estimated 767,000 disability-adjusted life years (DALYs) [1]. According to the 2009 World Malaria Report, the estimated population at risk of malaria in Côte d'Ivoire

\footnotetext{
*Correspondence: giovanna.raso@gmail.com

${ }^{\dagger}$ Equal contributors

'Département Environnement et Santé, Centre Suisse de Recherches Scientifiques en Côte d'Ivoire, BP 1303, Abidjan 01, Côte d'Ivoire

${ }^{2}$ Department of Epidemiology and Public Health, Swiss Tropical and Public Health Institute, P.O. Box, CH-4002 Basel, Switzerland

Full list of author information is available at the end of the article
}

was 21 million people; hence $100 \%$ of the population. There were an estimated 1.8 million suspected malaria cases, 33,000 in-patient cases and 18,000 deaths due to malaria [2]. The coverage with insecticide-treated nets (ITNs) has been estimated at only $13 \%$ in Côte d'Ivoire, with $6 \%$ of the households possessing at least one ITN and $4 \%$ of children aged under five years sleeping under an ITN. Although the artemisinin-based combination therapy (ACT) policy has been adopted by the country, these treatments are not yet available free of charge for children aged under five years. Strikingly, due to the post-election crisis starting in late 2010 [3], there was a provisional stopping of support by the Global Fund to Fight AIDS, Tuberculosis

\section{Biomed Central}


and Malaria (Global Fund in short), and hence the planned interventions by the national malaria control programme could not take place. Indeed, the lack of access to appropriate treatment emerged as an urgent public health issue.

With the end of the crisis in mid-2011 and the stability of the country slowly returning [3], the national malaria control programme has re-started its activities, and there is a pressing need for tools that can be implemented rapidly and cost-effectively to mitigate the burden of malaria. Highresolution predictive risk maps can assist authorities to spatially target interventions according to local needs. Such risk maps are typically based on regression models employing climatic and other environmental factors as covariates due to their important role in malaria transmission. A number of studies have shown that Plasmodium infections are influenced by environmental factors such as temperature, rainfall, humidity and elevation [4-8]. These factors directly or indirectly influence the development and occurrence of Anopheles mosquitoes, the malaria vectors, and hence, affect the geographical distribution of malaria.

Standard statistical modelling approaches assume independence between survey locations and neglect potential spatial dependency between neighbouring locations due to unobserved common exposures. Geo-statistical models take into account spatial correlation by additional location-specific random effect parameters. These models have already been applied to model malaria risk at different geographical scales in sub-Saharan Africa [5,9-19].

In Côte d'Ivoire, there is considerable climatic variation from north to south, leading to the sub-division of the country into different ecological zones. Isotropic geostatistical models assume that spatial correlation is a function of distance between locations irrespective of locations themselves. However, spatial correlation might vary across the country due to the presence of different ecological regions, variation in health system performance, socioeconomic differentials or intervention coverage, introducing non-stationarity. Non-stationary models had previously been applied to model malaria risk in western Côte d'Ivoire, Mali and western sub-Saharan Africa [12-14].

Given the need and the lack of contemporary national malaria surveys in Côte d'Ivoire (i.e. malaria indicator surveys - MIS), this work used a geo-statistical modelling approach for point-prevalence data from a wide array of sources for children under the age of 16 years to predict malaria risk in Côte d'Ivoire, including uncertainty measures. The modelling approach was adjusted for key environmental risk factors.

\section{Methods}

\section{Study area}

Côte d'Ivoire is located in West Africa and has an area of $322,462 \mathrm{~km}^{2}$. It borders the countries of Liberia and Guinea in the west, Mali and Burkina Faso in the north and Ghana in the east. The total population is estimated at 21 million. The climate of Côte d'Ivoire is generally warm and humid, ranging from equatorial in the southern coasts and tropical in the centre to semi-arid in the far north. There are three seasons: warm and dry (November to March), hot and dry (March to May), and hot and wet (June to October). The temperature averages between $25^{\circ} \mathrm{C}$ and $32^{\circ} \mathrm{C}$ and ranges from $10^{\circ} \mathrm{C}$ to $40^{\circ} \mathrm{C}$. The south-eastern part of Côte d'Ivoire is marked by coastal inland lagoons that start at the Ghanaian border and stretch $300 \mathrm{~km}$ along the eastern half of the coast. The southern region, especially the south-west, is covered with dense tropical moist forest. The Guinean forest-savannah mosaic belt extends across the middle of the country from east to west. The northern part of Côte d'Ivoire belongs to the West Sudanian savannah.

\section{Data sources}

A systematic search was carried out on PubMed to identify all surveys that reported Plasmodium spp. prevalence data for Côte d'Ivoire. The authors' own bibliographies were also systematically searched. Additionally, a broad-based search of grey literature was conducted, including local journals, MSc and $\mathrm{PhD}$ theses from national universities and libraries of research institutes, Ministry of Health $(\mathrm{MoH})$ reports and personal communication. The period covered was between 1988 and 2007. In case geographical coordinates of malaria point prevalence data were missing from the literature, the locations were searched on a map and the respective coordinates extracted. Whenever possible, authors were contacted for provision of supplementary information on the reported data. Given that most of the studies focused on children, it was decided that for modelling purposes, only prevalence data for children aged $<16$ years were to be assembled. In case older age groups were also sampled in a particular study, the authors were asked to provide individual level data, so that the prevalence for the target age group (i.e. $<16$ years) could be extracted. For each data point, the agespecific number of children examined and the percentage tested positive for Plasmodium spp. infection were extracted. Additionally, the year when the survey was carried out was recorded. The prevalence data used in this study are available upon request from the authors.

Elevation (altitude above sea level, expressed in $\mathrm{m}$ ) was obtained from USGS EROS data centre digital elevation model (DEM) at a spatial resolution of $1 \mathrm{~km}$. Distance to the nearest water body (in $\mathrm{m}$ ) was computed based on the Health Mapper data files for rivers, lakes and wetlands. Summarized estimates for eight-day maximum land surface temperature (LST) and 16-day normalized difference vegetation index (NDVI) were obtained from Moderate Resolution Imaging Spectroradiometer (MODIS) at a spatial resolution of $1 \mathrm{~km}$ during the period from 2000 to 2008. Ten-day rainfall data were obtained from the Africa 
Data Dissemination Service (ADDS) at a spatial resolution of $8 \mathrm{~km}$. At each location the mean annual maximum temperature, mean annual rainfall, elevation and distance to water bodies were extracted.

Ecological zones were derived by importing rainfall, elevation, NDVI, land cover and maximum temperature data into ERDAS Imagine 9.3 software. An unsupervised classification via the iterative self-organizing data analysis technique (ISODATA) was used on the above ecological factors to create three different ecological zones based on between-class similarities. Centroids of each ecological zone in Côte d'Ivoire were derived via ArcMap version 9.2 (ESRI) for subsequent modelling purposes.

\section{Statistical analysis}

Binomial regression models were fitted in STATA/IC version 10.1 (StataCorp LP; College Station, TX, USA) to assess the relation between ecological predictors and Plasmodium spp. prevalence. Significant ecological factors, based on likelihood ratio test (LRT) with significance levels of $15 \%$, were included as covariates in further analyses. Bayesian non-spatial and geo-statistical logistic regression models were fitted in OpenBUGS version 3.0.3 (Imperial College and Medical Research Council; London, UK). Spatial dependency was modelled assuming stationary (i.e. spatial correlation was modelled as a function of distance between locations only), as well as non-stationary (i.e. spatial correlation was modelled as a function of distance between locations and position within the study area) latent spatial processes.

\section{Model formulation}

Let $N_{i}$ be the number of children tested at location $s_{i}(\mathrm{i}=1$, $\ldots, n)$ and $Y_{i}$ the number of those found with Plasmodium parasites in a blood sample. It was assumed that $Y_{i}$ arises from a binomial distribution, that is $Y_{i} \sim \operatorname{Bin}\left(N_{i}, p_{i}\right)$, with $p_{i}$ measuring malaria risk at location $s_{i}$. The relation between the malaria risk and the $m$ associated environmental covariates $X_{i}$ at location $s_{\dot{v}} X_{i}=\left(X_{i 1}, X_{i 2}, \ldots, X_{i m}\right)^{T}$, was modelled via the logistic regression $\operatorname{logit}\left(p_{i}\right)=X_{i}^{T} \beta$, where $\beta=\left(\beta_{1}, \beta_{2}\right.$, $\left.\ldots, \beta_{p}\right)^{T}$ are the regression coefficients. Exchangeable random effects $\varepsilon_{i}$ were added on the logit scale, such as $\operatorname{logit}\left(p_{i}\right)=X_{i}^{T} \beta+\varepsilon_{i}$.

Spatial correlation was introduced on location-specific random effect parameters $\varphi_{i}$, that is $\operatorname{logit}\left(p_{i}\right)=X_{i}^{T} \beta+\varphi_{i}$, assuming that $\varphi=\left(\varphi_{1}, \varphi_{2}, \ldots, \varphi_{n}\right)^{T} \sim M V N(0, \Sigma)$ with variance-covariance matrix $\Sigma$. It was further assumed that spatial process is isotropic and decays exponentially with distance, i.e. $\Sigma_{i j}=\sigma^{2} \exp \left(-\rho d_{i j}\right)$, where $d_{i j}$ is the Euclidean distance between villages $s_{i}$ and $s_{j} ; \sigma^{2}$ is the geographic variability known as sill, and $\rho$ is a smoothing parameter that controls the rate of correlation decay with increasing distance. The spatial range is defined as the minimum distance at which spatial correlation between locations is below $5 \%$, and is calculated as $3 / \rho$ for the exponential correlation structure.

To take into account non-stationarity, the study area was partitioned into three ecological sub-regions $(K=3)$, assuming local independent stationary spatial processes $\omega_{k}=\left(\omega_{k 1}, \omega_{k 2}\right.$, $\left.\ldots, \omega_{k N}\right)^{T}$ in each ecological sub-region $(k=1, \ldots, K)$. The spatial processes were assumed to be multi-variate normally distributed, $\omega_{k} \sim \operatorname{MVN}\left(0, \Sigma_{k}\right)$, with variance-covariance matrixes $\Sigma_{k}$ defined by $\left(\Sigma_{k}\right)_{i j}=\sigma_{k}^{2} \exp \left(\rho_{k} d_{i j}\right)$. It was further considered that the spatial correlation $\varphi_{i}$ at location $\mathrm{s}_{i}$ in the study area is a mixture of the independent spatial processes modelled as weighed average, such as $\varphi i=\sum_{k=1}^{K} a_{i k} \omega_{i k}$, where the weights $a_{i k}$ are decreasing functions of the distance between location $s_{i}$ and the centroids of the sub-regions $k[20,21]$. Under these specifications, $\varphi$ follows a multivariate normal distribution, $\varphi \sim$ $\operatorname{MVN}\left(0, \sum_{k=1}^{K} A_{k}^{T} \Sigma_{k} A_{k}\right)$, where $A_{k}=\operatorname{diag}\left(a_{1 k}, a_{2 k}, \ldots, a_{n k}\right)$.

In a Bayesian modelling framework, specification of prior distributions of all model parameters is required. Vague normal priors with large variance were assumed for the $\beta$ parameters, while inverse gamma priors were chosen for $\sigma^{2}$ and $\sigma_{k}^{2}$ and uniform priors for $\rho$ and $\rho_{k}$. Markov chain Monte Carlo (MCMC) simulation was employed to estimate the model parameters [22]. A single chain sampler with a burnin of 2,000 iterations was run for around 100,000 iterations. Convergence was assessed by inspection of ergodic averages of selected model parameters. The deviance information criterion (DIC) was used to assess the goodness-of-fit of the models without and with exchangeable random effects, and the stationary and non-stationary geo-statistical models [23]. The smaller the DIC, the better the model fit. Finally, Bayesian kriging was used to generate smooth risk maps for Plasmodium infection prevalence based on the parameter estimates of the best fitting model [24].

\section{Results}

\section{Identified studies and description of georeferenced survey data}

The systematic and broad-based search revealed a total of 29 data sources (17 peer-reviewed articles, six theses, four reports and two personal communications) for a 20-year period starting in 1988. A total of 235 data points with malaria prevalence data for individuals aged $<16$ years (at 170 unique survey locations) were extracted, of which 53 (22.6\%) pertained to surveys carried out between 1988 and 1999, and the remaining 182 data points (77.4\%) were collected between 2000 and 2007. A third of the data points $(n=80$, $34.0 \%$ ) were located in the region of Man in western Côte d'Ivoire arising from two large cross-sectional surveys carried out in 2001 and 2003/2004. Figure 1 shows the spatial distribution of data points within Côte d'Ivoire and the extent of the derived ecozones in the background, stratified by survey year. Ecozone III had considerably 


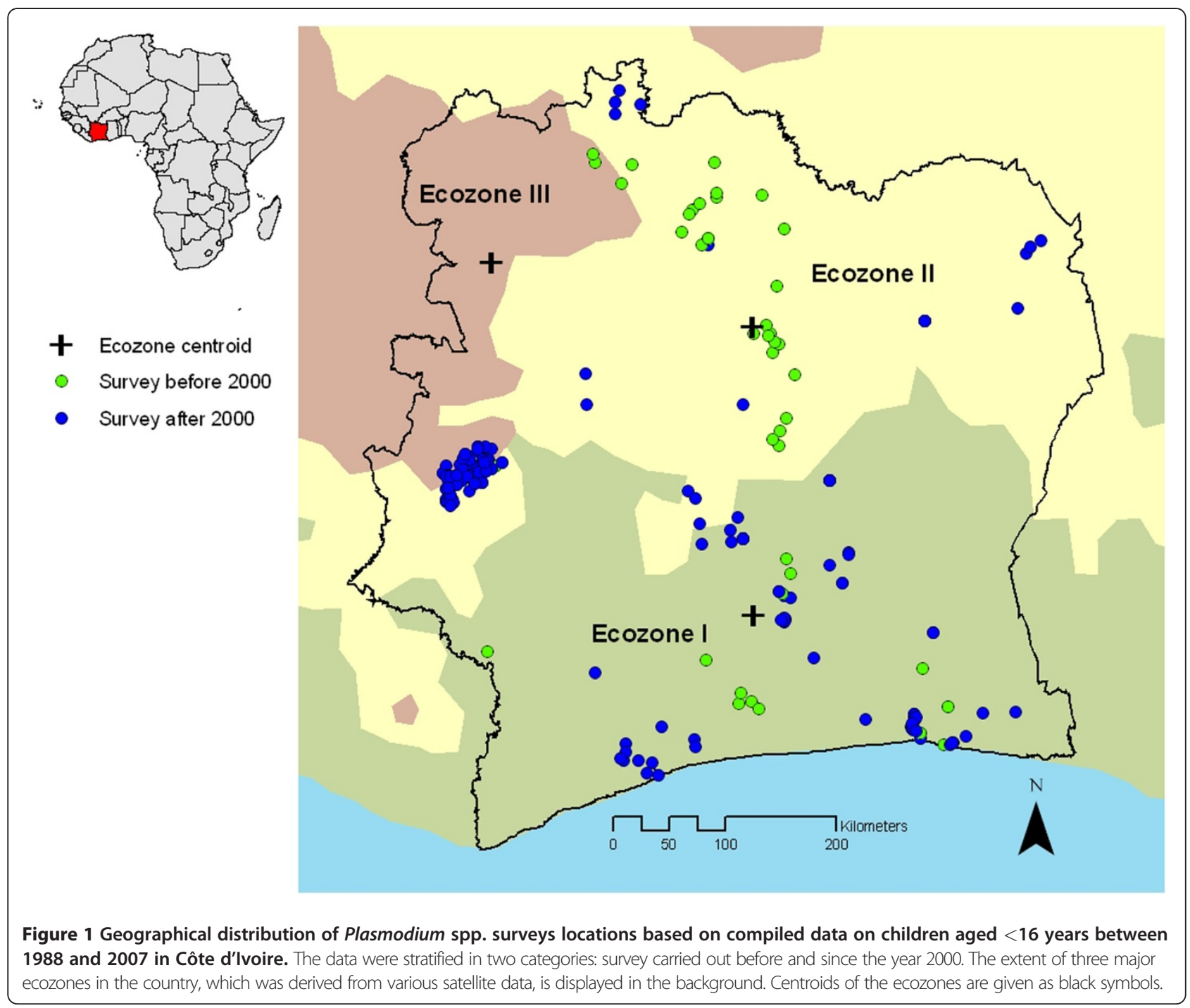

fewer data points, most of which were concentrated at the southern border of the zone. In contrast, in ecozones I and II, data points were well distributed across the regions.

\section{Plasmodium spp. prevalence}

For subsequent logistic regression analyses, data on Plasmodium spp. prevalence were used. Surveys with missing information on Plasmodium spp. was assumed as Plasmodium falciparum prevalence since other species, i.e. Plasmodium ovale and Plasmodium malariae, are much less frequent in Côte d'Ivoire [25-30]. The Plasmodium prevalence in children $<16$ years ranged from nil to $100 \%$ with a mean prevalence of $54.1 \%$. The observed prevalence at the data points distributed over the country is shown in Figure 2. In south Côte d'Ivoire, Plasmodium prevalence is generally lower compared to the rest of the country. Indeed, when subdividing Côte d'Ivoire into three equally large strata from lowest to highest latitude, namely south, central and north, the mean prevalence of Plasmodium was $37.3 \%, 61.5 \%$ and $61.0 \%$, respectively.

\section{Non-spatial regression analysis}

Table 1 shows the results of the non-spatial and spatial logistic regression analyses. The non-spatial multivariate model (model 1) revealed that elevation and distance to closest rivers were significantly positively associated with Plasmodium spp. prevalence, while rainfall and maximum LST were negatively associated. When introducing exchangeable random effects (model 2), model performance based on DIC estimates improved considerably $(9,974$ vs. 1,501$)$. The random effect had also an influence on the regression parameters of the covariates. Association with distance to rivers became non-significant, while stronger negative effects of the covariates rainfall and maximum LST on the outcome were observed. 


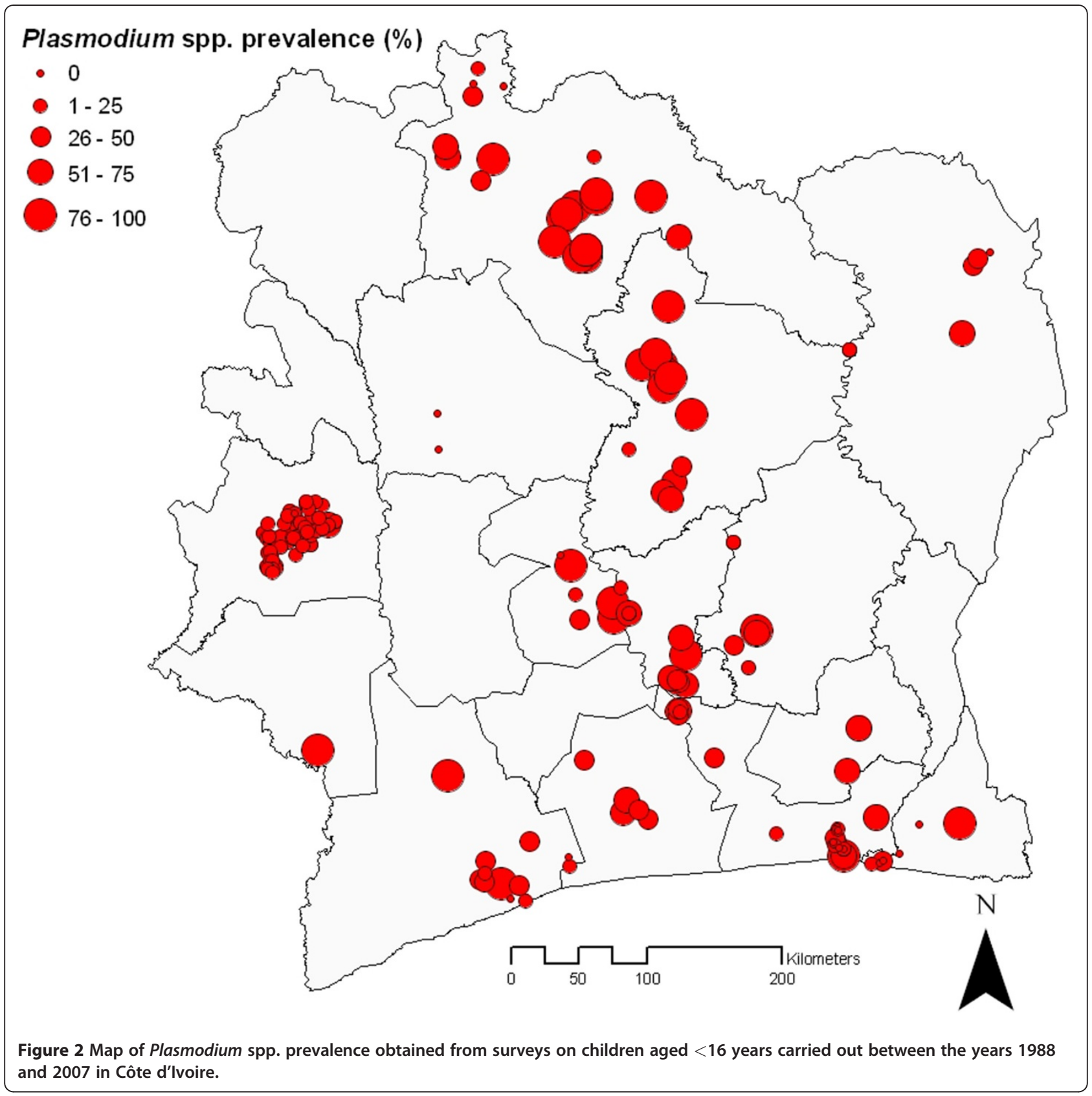

\section{Spatial regression analysis}

The introduction of location-specific stationary random effect parameters into the model (model 3) showed a strong leverage on model performance and parameter estimates compared to model 2. Elevation became nonsignificantly related to the outcome, leaving the model with only rainfall and maximum LST as significant covariates. The model fit based on DIC estimates improved considerably $(1,485)$. When looking at the results of the non-stationary model (model 4 ), the DIC decreased further $(1,479)$, suggesting that this is the best model. Of note, for model 4 the covariates elevation and distance to closest rivers were non-significant as well, whereas rainfall and maximum LST remained significant, as it had been observed for the other models.

Model 3 estimated a larger geographic variability $\sigma^{2}$ compared to the non-spatial model 2 (2.37 vs. 1.59). The geographic variability $\sigma_{2}^{2}$ estimated for ecozone II from the non-stationary model was particularly large compared to $\sigma_{1}{ }^{2}$ and $\sigma_{3}{ }^{2}$. The estimated spatial range (above which spatial correlation drops below 5\%) from the stationary model 3 was about $151 \mathrm{~km}$. However, taking into account non-stationarity, the spatial range varied between $8 \mathrm{~km}$ (ecozone I) and $193 \mathrm{~km}$ (ecozone II). 
Table 1 Parameter estimates based on logistic regression models for Plasmodium spp. prevalence in children aged $<16$ years in Côte d'Ivoire using compiled data from surveys carried out between 1988 and 2007

\begin{tabular}{|c|c|c|c|c|c|c|c|c|}
\hline \multirow[t]{2}{*}{ Model parameter } & \multicolumn{2}{|c|}{$\begin{array}{l}\text { Non-spatial model } \\
\text { (Model 1) }\end{array}$} & \multicolumn{2}{|c|}{$\begin{array}{l}\text { Non-spatial model with } \\
\text { exchangeable random effects } \\
\text { (Model 2) }\end{array}$} & \multicolumn{2}{|c|}{$\begin{array}{l}\text { Stationary spatial model } \\
\text { (Model 3) }\end{array}$} & \multicolumn{2}{|c|}{$\begin{array}{l}\text { Non-stationary spatial mode } \\
\text { (Model 4) }\end{array}$} \\
\hline & $\overline{\mathrm{OR}^{\mathrm{a}}}$ & $\mathrm{BCl}^{\mathrm{b}}$ & $\mathrm{OR}^{\mathrm{a}}$ & $\mathrm{BCl}^{\mathrm{b}}$ & $\mathrm{OR}^{\mathrm{a}}$ & $\mathrm{BCl}^{\mathrm{b}}$ & $\mathrm{OR}^{\mathrm{a}}$ & $\mathrm{BCl}^{\mathrm{b}}$ \\
\hline Elevation & 1.44 & $1.40,1.48$ & 1.07 & $1.01,1.13$ & 1.05 & $0.99,1.11$ & 1.05 & $0.98,1.11$ \\
\hline Distance to rivers & 1.08 & $1.06,1.11$ & 1.02 & $0.94,1.10$ & 0.98 & $0.91,1.06$ & 0.98 & $0.91,1.05$ \\
\hline Mean rainfall & 0.91 & $0.88,0.94$ & 0.73 & $0.67,0.79$ & 0.77 & $0.70,0.83$ & 0.76 & $0.70,0.83$ \\
\hline Mean maximum $\mathrm{LST}^{\mathrm{c}}$ & 0.89 & $0.86,0.92$ & 0.67 & $0.60,0.74$ & 0.72 & $0.65,0.80$ & 0.72 & $0.64,0.79$ \\
\hline$\sigma^{2}$ & & & 1.59 & $1.20,2.09$ & 2.37 & $1.29,4.74$ & & \\
\hline$\sigma^{2}{ }_{1}$ (ecozone I) & & & & & & & 1.56 & $0.78,2.67$ \\
\hline$\sigma_{2}^{2}$ (ecozone II) & & & & & & & 4.76 & $2.05,10.49$ \\
\hline$\sigma_{3}^{2}$ (ecozone III) & & & & & & & 0.10 & $0.006,0.40$ \\
\hline$\rho$ & & & & & 1.98 & $0.70,3.82$ & & \\
\hline$\rho_{1}$ (ecozone I) & & & & & & & 39.44 & $12.02,59.35$ \\
\hline$\rho_{2}$ (ecozone II) & & & & & & & 1.55 & $0.52,3.23$ \\
\hline$\rho_{3}$ (ecozone III) & & & & & & & 27.61 & $2.30,57.62$ \\
\hline$D_{I} C^{d}$ & 9,974 & & 1,501 & & 1,485 & & 1,479 & \\
\hline
\end{tabular}

${ }^{\mathrm{a} O R}$ Odds ratio; ${ }^{\mathrm{b}} B C I$ Bayesian credible interval; ${ }^{\mathrm{c}} L S T$ Land surface temperature; ${ }^{\mathrm{d}} D I C$ Deviance information criterion.

\section{Risk mapping}

Figure 3 shows the predicted malaria risk map for Côte d'Ivoire as obtained from the best fitting model, namely the non-stationary logistic regression model (model 4). Highest malaria prevalence $(>70 \%)$ was predicted in the north-central part and in the western part of Côte d'Ivoire. In contrast, low prevalence estimates $(\leq 30 \%)$ were predicted for the following areas: (i) in the north at the country border, (ii) in the north-east, (iii) in the south-east around the economic capital Abidjan, and (iv) in the central-west between two high prevalence areas. Noteworthy, model prediction of the largest low prevalence area occurred in the north-east, but the model estimates in this area were based on a single data point.

\section{Uncertainty of the malaria risk map for Côte d'Ivoire}

The standard deviation map of the predictive posterior distribution obtained from model 4 is given in Figure 4. As expected, it depicts low prediction error around the survey locations. For instance, in the north-eastern part of Côte d'Ivoire where low prevalence of Plasmodium spp. was predicted, the error rapidly increases with increasing distance from survey locations. This area in the north-east of Côte d'Ivoire has only few survey data, and hence standard deviations were overall high.

\section{Discussion}

Most malaria-related deaths, morbid sequelae and economic losses could be averted through implementation of control measures with a proven track record, such as ITNs, indoor residual spraying (IRS) and access to prompt diagnosis and treatment using ACT to those populations in highest need [31]. Since 2007 and until the post-election crisis that emerged in November 2010, malaria control in Côte d'Ivoire has been largely funded by the Global Fund. However, much remains to be done to significantly reduce the burden of malaria through large-scale implementation of control interventions [2]. It is conceivable that the sociopolitical conflict and unrest that prevailed for most of the past 12 years, hindered progress on malaria control among other pressing public health issues $[3,32,33]$. Indeed, during the most recent armed conflict, malaria interventions were interrupted altogether. Now that political stability has resumed, there is a pressing need to re-establish and strengthen health systems, preventive measures and disease control programmes. The aim of this study was to provide a country-wide map of the geographical distribution of malaria risk that could help in the spatial planning of future control interventions by the national malaria control programme, readily adapted to local needs and current capacities.

Previous efforts obtained global, regional or continentwide estimates, which included Côte d'Ivoire [5,10]. However, these previous estimates captured the variation of malaria risk at large spatial scales, and the accuracy at high resolution may be compromised. In fact, countries with the same climatic conditions may not have the same disease burden because country-specific factors (e.g. different intervention coverage, performance of health systems) may modify the risk. Indeed, in several areas of Côte d'Ivoire, the health system was heavily affected or partially interrupted in the last decade [32]. The malaria 


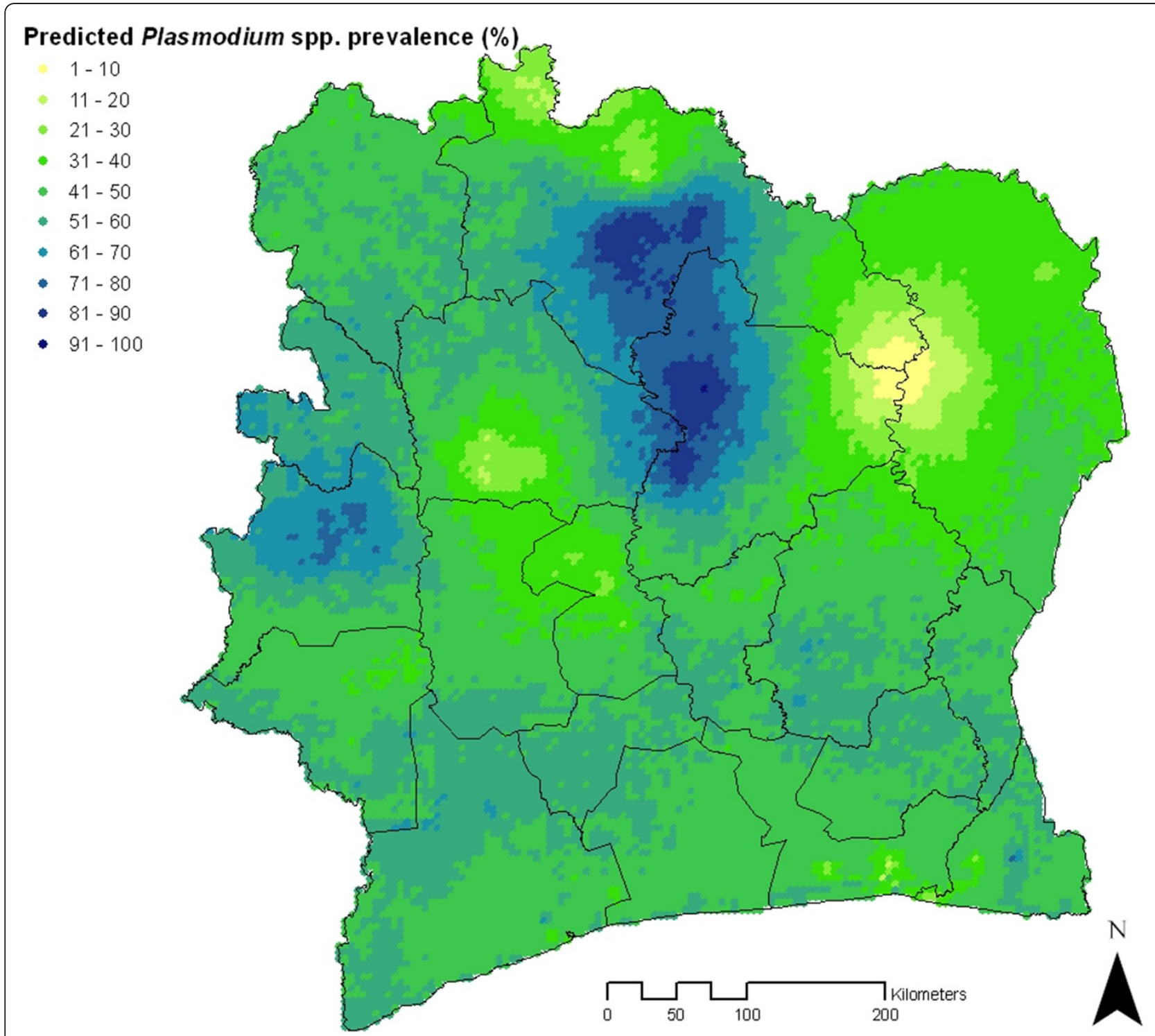

Figure 3 Smoothed risk map of Plasmodium spp. infection for children aged $<16$ years in Côte d'Ivoire using a Bayesian non-stationary logistic regression model.

risk map presented in this article shows that there is spatial variation in the prevalence of Plasmodium spp. infection. This is also observed in the newly produced global $P$. falciparum map, but differences are apparent, especially with regard to zones where the present model predicts low prevalence [34]. Another previous map produced at regional scale for West and Central Africa also revealed spatial variation [5], but differences, especially for low prevalence rates $(<30 \%)$, can also be observed with the current map.

Overall, 235 geo-referenced malaria prevalence survey data points were obtained. Bayesian geo-statistical methods were used to model the point prevalence data, using logistic regression models with key environmental covariates derived from remotely sensed data. Two nonspatial and two spatial models were fitted with elevation, distance to rivers, rainfall and maximum LST employed as environmental covariates. For the spatial models, the assumption of stationarity was extended to non-stationarity of the spatial process, in line with previous work [11-14,21,35]. Ecological zoning was considered to partition the study area into meaningful sub-regions with locally distinct ecological characteristics. Indeed, the models employed here confirmed that spatial correlation differed depending on the 


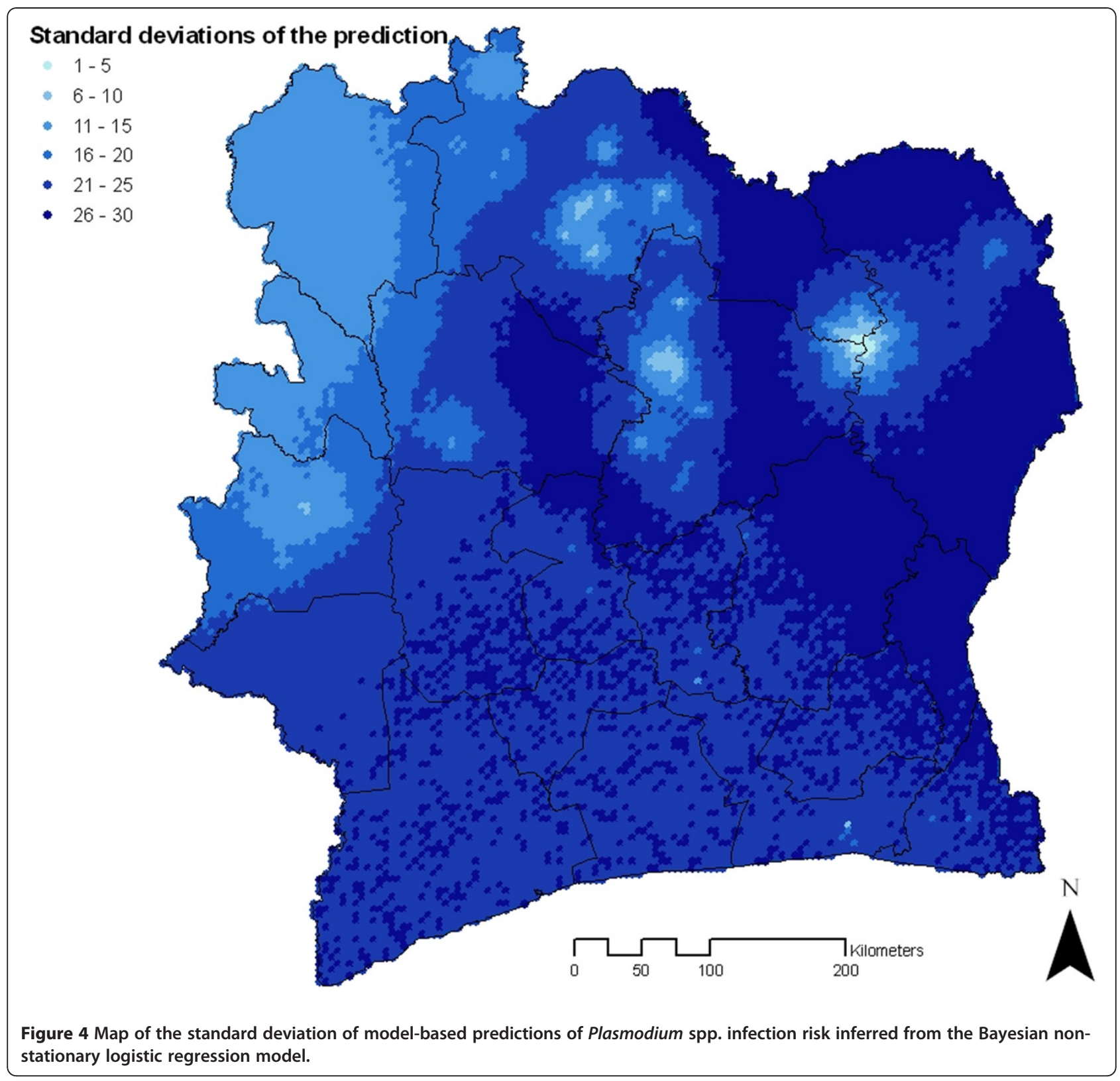

location (ecozone) and that the non-stationary spatial model was superior to the remaining models in predicting Plasmodium spp. prevalence.

In the spatial models, the covariates rainfall and maximum LST were significantly associated with Plasmodium prevalence. These environmental factors had already been successfully implemented in previous geo-statistical modelling approaches employed in other African countries $[5,8,13,36]$. Côte d'Ivoire has spatially distinct climate conditions that vary from equatorial in the south coast, to tropical in the centre, and semi-arid in the north, with more rainfall in the south compared to the north, and higher temperature amplitudes in the north compared to the south, which might explain the significant contribution that these covariates had in the spatial models. Although other environmental covariates such as elevation and distance to rivers were significant in the non-spatial models, they became non-significant in the spatial models. This demonstrates the importance of accounting for spatial correlation, when analysing geographical data in order to avoid over-estimation of the standard errors of model covariates [37]. Topographically, Côte d'Ivoire can be considered as a vast plateau, with exception of the west of the country (Dix-Huit Montagnes region), which has mountains with peaks of 1,000 $\mathrm{m}$ and above (the highest elevation is Mount Nimba, 1,752 m above sea level, located along the border with Guinea). Previous work from this region demonstrated that elevation, rainfall and temperature have no influence on the spatial distribution of 
Plasmodium prevalence at small scale [14]. The current study confirms that the effect of elevation on malaria prevalence at country-level is insignificant for Côte d'Ivoire. However, rainfall and temperature were identified to be important drivers of Plasmodium spp. prevalence at a larger scale. Of note, rainfall was found to drive Plasmodium parasitaemia also at small scale in the mountainous part of western Côte d'Ivoire [13].

The present results are based on compiled survey data assembled for Côte d'Ivoire covering a 20-year period until 2008. There are several issues related to the use of assembled data worth discussing. First, the distribution of survey data was very rich, especially in the west (region of Man), south and central part of the country, while data availability was extremely sparse in the north-west and north-east. Hence, the predicted prevalence estimates should be interpreted with caution and in combination with the map of uncertainty (Figure 4). For instance, the model predicted low Plasmodium prevalence in the north-east of Côte d'Ivoire based on only one data point and, given the high spatial correlation and the scarcity of data in this region (also due to low population density), the model predicted a relatively large area with low prevalence, which might not reflect the real situation. Fortunately, Bayesian geo-statistical modelling allows inferring measures of uncertainties from the model-based predictions, which can help in the interpretation of the risk maps. Second, many of the surveys lack Plasmodium species-specific information and therefore it was decided to model Plasmodium spp. rather than species-specific prevalence. Malaria, however, is not a single disease and there are five Plasmodium species that cause human malaria, which are transmitted by over 30 Anopheles mosquito species [38]. This entails different disease spectra in different population target groups from different epidemiological settings, with implications for current malaria control programmes [38]. Hence, future studies need to make an effort to consistently and correctly report species-specific information on Plasmodium prevalence in order to improve control. Despite this shortcoming, it must be mentioned that in Cote d'Ivoire, P. falciparum is the predominant species, as consistently shown across the country [25-30]. Hence, the Plasmodium spp. risk map presented here is closely imitating a $P$. falciparum risk map. Third, the models were not adjusted for age although it is well acknowledged that malaria prevalence differs between age groups [39]. Therefore, future modelling should take into account the age-prevalence-relation via mathematical transmission models [40,41] converting age-heterogeneous survey data to a common measure which is used for mapping purposes $[9,10]$. Fourth, remotely sensed climate data (rainfall and maximum LST) were used to calculate mean values over the period from 2000 to 2008, although obtained prevalence data dated back to 1988. This period was chosen because MODIS data (maximum LST) were not available before the year 2000, and alignment with historical temperature data was not successful. Although it might be expected that models with year-specific climate variables could result in better model fits, the use of mean climatic values reduces the effect of abnormal climatic conditions that might have occurred during the study period, avoiding artefacts in the parameter estimates.

\section{Conclusion}

Although the need for evaluating the value of detailed disease incidence and prevalence maps to inform programmatic responses in evaluation and surveillance at a global scale has been expressed, malaria risk mapping at national level is crucial to support and plan interventions according to local needs in countries where control or elimination strategies are underway [42]. Côte d'Ivoire is currently focusing efforts on scaling up malaria control interventions. The current malaria risk map and future maps taking into account the latest prevalence data can provide detailed information on transmission changes and assist in monitoring and evaluation of current control activities of the re-established malaria control programme.

In the past, at present and in the future, Plasmodium spp. risk maps have guided and will continue to guide decision makers in Côte d'Ivoire and elsewhere for spatial targeting of malaria control activities, e.g. assisting estimates on case management and related procurement of ACT and rapid diagnostic tests and where to prioritize ITN and IRS activities. Although risk maps using historical data have to be interpreted with caution, Bayesian geo-statistical risk mapping provides information on the uncertainty of the model-based malaria risk estimates. Nonetheless, the results indicate that there is a need of more detailed malaria prevalence data in Côte d'Ivoire, preferentially obtained from a national survey on randomly selected locations, with species-specific information. Furthermore, the usability of routine data collected by a re-invigorated health system in Côte d'Ivoire should be explored without delay. Future risk mapping approaches might be improved by including information on intervention coverage, vector distribution and human population density, distribution and movement patterns.

\section{Abbreviations \\ ACT, Artemisinin-based combination therapy; ADDS, Africa Data \\ Dissemination Service; BCI, Bayesian credible interval; DALY, Disability- adjusted life year; DEM, Digital elevation model; DIC, Deviance information criterion; ITN, Insecticide-treated net; ISODATA, Iterative self-organizing data analysis technique; LST, Land surface temperature; MCMC, Markov chain Monte Carlo; MIC, Malaria indicator survey; MODIS, Moderate Resolution Imaging Spectroradiometer; NDVI, Normalized difference vegetation index.}




\section{Authors' contributions}

GR, NS, BGK and EST performed the systematic searches and geo-referenced malaria survey data. GR, JU, BGK, FR, EKN, KDS, SA and BM contributed malaria survey data. GR and NS carried out the spatial analyses and interpretation of the data and drafted the manuscript. JU, BGK, EST, KDS, FR, EKN, SA, BM, MT and PV assisted with the interpretation of the data and the revision of the manuscript. All authors read and approved the final manuscript.

\section{Acknowledgements}

Thanks are addressed to Drs A B Tschannen and F Staubli-Asobavire for providing malaria survey data. GR, JU and PV acknowledge financial support from the Swiss National Science Foundation (project numbers 32003B132949/1, IZ70Z0_123900 and 325230-118379, respectively).

\section{Author details}

'Département Environnement et Santé, Centre Suisse de Recherches Scientifiques en Côte d'Ivoire, BP 1303, Abidjan 01, Côte d'Ivoire. ${ }^{2}$ Department of Epidemiology and Public Health, Swiss Tropical and Public Health Institute, P.O. Box, CH-4002 Basel, Switzerland. ${ }^{3}$ University of Basel, P.O. Box, CH-4003 Basel, Switzerland. ${ }^{4}$ UFR Sciences de Nature, Université d'Abobo-Adjamé, 02 BP 801, Abidjan 02, Côte d'Ivoire. ${ }^{5}$ Vector Group, Liverpool School of Tropical Medicine, Pembroke Place, Liverpool, L3 5QA, United Kingdom. ${ }^{6}$ UFR Biosciences, Université de Cocody, 22 BP 522, Abidjan 22. Côte d'Ivoire. ${ }^{7}$ Global Alliance for Improved Nutrition, P.O. Box 55 Rue de Vermont 37-39, CH-1211, Geneva 20, Switzerland. ${ }^{8}$ Swiss Centre for International Health, Swiss Tropical and Public Health Institute, P.O. Box, CH4002 Basel, Switzerland. ${ }^{9}$ Programme National de Lutte Contre le Paludisme, BP V4, Abidjan, Côte d'Ivoire. ${ }^{10}$ Institut Pierre Richet, 01 BP 1500, Bouaké 01, Côte d'Ivoire.

Received: 28 October 2011 Accepted: 23 April 2012

Published: 9 May 2012

\section{References}

1. WHO: The World Health Report 2004: Changing history. Geneva: World Health Organization; 2004

2. WHO: World Malaria Report 2009. Geneva: World Health Organization; 2009

3. Bonfoh B, Raso G, Koné I, Dao D, Girardin O, Cissé G, Zinsstag J, Utzinger J، Tanner M: Research in a war zone. Nature 2011, 474:569-571.

4. Cohen JM, Ernst KC, Lindblade KA, Vulule JM, John CC, Wilson ML: Topographyderived wetness indices are associated with household-level malaria risk in two communities in the western Kenyan highlands. Malar J 2008, 7:40

5. Gemperli A, Sogoba N, Fondjo E, Mabaso M, Bagayoko M, Briët OJT, Anderegg D, Liebe J, Smith T, Vounatsou P: Mapping malaria transmission in West and Central Africa. Trop Med Int Health 2006, 11:1032-1046.

6. Bouvier P, Rougemont A, Breslow N, Doumbo O, Delley V, Dicko A, Diakite M, Mauris A, Robert CF: Seasonality and malaria in a West African village: does high parasite density predict fever incidence? Am J Epidemiol 1997, 145:850-857.

7. Rogers DJ, Randolph SE: The global spread of malaria in a future, warmer world. Science 2000, 289:1763-1766.

8. Hay SI, Cox J, Rogers DJ, Randolph SE, Stern DI, Shanks GD, Myers MF, Snow RW: Climate change and the resurgence of malaria in the East African highlands. Nature 2002, 415:905-909.

9. Gemperli A, Vounatsou P, Sogoba N, Smith T: Malaria mapping using transmission models: application to survey data from Mali. Am J Epidemiol 2006, 163:289-297.

10. Hay SI, Guerra CA, Gething PW, Patil AP, Tatem AJ, Noor AM, Kabaria CW, Manh BH, Elyazar IRF, Brooker S, Smith DL, Moyeed RA, Snow RW: A world malaria map: Plasmodium falciparum endemicity in 2007. PLoS Med 2009, 6:e1000048

11. Gosoniu L, Vounatsou P, Sogoba N, Maire N, Smith T: Mapping malaria risk in West Africa using a Bayesian nonparametric non-stationary model. Comput Stat Data Anal 2009, 53:3358-3371.

12. Gosoniu L, Vounatsou P, Sogoba N, Smith T: Bayesian modelling of geostatistical malaria risk data. Geospat Health 2006, 1:127-139.

13. Raso G, Silué KD, Vounatsou P, Singer BH, Yapi A, Tanner M, Utzinger J, N'Goran EK: Spatial risk profiling of Plasmodium falciparum parasitaemia in a high endemicity area in Côte d'Ivoire. Malar J 2009, 8:252.

14. Silué KD, Raso G, Yapi A, Vounatsou P, Tanner M, N'Goran EK, Utzinger J: Spatially-explicit risk profiling of Plasmodium falciparum infections at a small scale: a geostatistical modelling approach. Malar J 2008, 7:111.
15. Matthys B, Vounatsou P, Raso G, Tschannen AB, Becket EG, Gosoniu L, Cissé G, Tanner M, N'Goran EK, Utzinger J: Urban farming and malaria risk factors in a medium-sized town in Côte d'Ivoire. Am J Trop Med Hyg 2006, 75:1223-1231.

16. Riedel N, Vounatsou P, Miller JM, Gosoniu L, Chizema-Kawesha E, Mukonka $\checkmark$, Steketee RW: Geographical patterns and predictors of malaria risk in Zambia: Bayesian geostatistical modelling of the 2006 Zambia national malaria indicator survey (ZMIS). Malar J 2011, 9:37.

17. Gosoniu L, Veta AM, Vounatsou P: Bayesian geostatistical modeling of Malaria Indicator Survey data in Angola. PLoS One 2011, 5:e9322.

18. Gosoniu L, Vounatsou P: Non-stationary partition modeling of geostatistical data for malaria risk mapping. J App/ Stat 2011, 38:3-13.

19. Machault V, Vignolles C, Borchi F, Vounatsou P, Pages F, Briolant S, Lacaux JP, Rogier C: The use of remotely sensed environmental data in the study of malaria. Geospat Health 2011, 5:151-168.

20. Banerjee S, Gelfand AE, Knight JR, Sirmans CF: Spatial modeling of house prices using normalized distance-weighted sum of stationary processes. J Bus Econ Stat 2004, 22:206-213.

21. Raso G, Vounatsou P, Gosoniu L, Tanner M, N'Goran EK, Utzinger J: Risk factors and spatial patterns of hookworm infection among schoolchildren in a rural area of western Côte d'Ivoire. Int J Parasitol 2006, 36:201-210.

22. Gelfand AE, Smith AFM: Sampling-based approaches to calculating marginal densities. J Am Stat Assoc 1990, 85:398-410.

23. Spiegelhalter DJ, Best N, Charlin BP, van der Linde A: Bayesian measures of model complexity and fit. J Roy Stat Soc, Ser B-Stat Methodol 2002, 64:583-639.

24. Diggle PJ, Tawn JA, Moyeed RA: Model-based geostatistics. J Roy Stat Soc C-Appl Stat 1998, 47:299-326

25. Raso G, Luginbühl A, Adjoua CA, Tian-Bi NT, Silué KD, Matthys B, Vounatsou $P$, Wang $Y$, Dumas ME, Holmes E, Singer BH, Tanner M, N'Goran EK, Utzinger $\mathrm{J}$ : Multiple parasite infections and their relationship to self-reported morbidity indicators in a community of rural Côte d'Ivoire. Int J Epidemiol 2004, 33:1092-1102.

26. Raso G, Utzinger J, Silué KD, Ouattara M, Yapi A, Toty A, Matthys $B$, Vounatsou P, Tanner M, N'Goran EK: Disparities in parasitic infections, perceived ill health and access to health care among poorer and less poor schoolchildren of rural Côte d'Ivoire. Trop Med Int Health 2005, 10:42-57.

27. Nzeyimana I, Henry MC, Dossou-Yovo J, Doannio JM, Diawara L, Carnevale $P$ : The epidemiology of malaria in the southwestern forests of the Ivory Coast (Tai region). Bull Soc Pathol Exot 2002, 95:89-94 (in French).

28. Koudou BG, Ghattas H, Essé C, Nsanzabana C, Rohner F, Utzinger J, Faragher BE, Tschannen AB: The use of insecticide-treated nets for reducing malaria morbidity among children aged 6-59 months, in an area of high malaria transmission in central Côte d'Ivoire. Parasit Vectors 2010, 3:91

29. Koudou BG, Tano Y, Keiser J, Vounatsou P, Girardin O, Klero K, Koné M, N'Goran EK, Cissé G, Tanner M, Utzinger J: Effect of agricultural activities on prevalence rates, and clinical and presumptive malaria episodes in central Côte d'Ivoire. Acta Trop 2009, 111:268-274.

30. Keiser J, N'Guessan NA, Adoubryn KD, Silué KD, Vounatsou P, Hatz C, Utzinger J, N'Goran EK: Efficacy and safety of mefloquine, artesunate, mefloquine-artesunate, and praziquantel against Schistosoma haematobium: randomized, exploratory open-label trial. Clin Infect Dis 2010, 50:1205-1213.

31. Gomez Sambo L: Defining and defeating the intolerable burden of malaria III. Progress and perspectives. Am J Trop Med Hyg 2007, 77 (Suppl 6):iii.

32. Betsi NA, Koudou BG, Cissé $G$, Tschannen AB, Pignol AM, Ouattara $Y$, Madougou Z, Tanner M, Utzinger J: Effect of an armed conflict on human resources and health systems in Côte d'Ivoire: prevention of and care for people with HIV/AIDS. AIDS Care 2006, 18:356-365.

33. Fürst $T$, Raso G, Acka CA, Tschannen AB, N'Goran EK, Utzinger J: Dynamics of socioeconomic risk factors for neglected tropical diseases and malaria in an armed conflict. PLoS Negl Trop Dis 2009, 3:e513.

34. Gething PW, Patil AP, Smith DL, Guerra CA, Elyazar IR, Johnston GL, Tatem AJ, Hay SI: A new world malaria map: Plasmodium falciparum endemicity in 2010. Malar J 2011, 10:378

35. Vounatsou P, Raso G, Tanner M, N'Goran EK, Utzinger J: Bayesian geostatistical modelling for mapping schistosomiasis transmission. Parasitology 2009, 136:1695-1705.

36. Snow RW, Gouws E, Omumbo J, Rapuoda B, Craig MH, Tanser FC, le Sueur D, Ouma J: Models to predict the intensity of Plasmodium falciparum 
transmission: applications to the burden of disease in Kenya. Trans $R$ Soc Trop Med Hyg 1998, 92:601-606.

37. Raso G, Matthys B, N'Goran EK, Tanner M, Vounatsou P, Utzinger J: Spatial risk prediction and mapping of Schistosoma mansoni infections among schoolchildren living in western Côte d'lvoire. Parasitology 2005, 131:97-108.

38. Alonso PL, Brown G, Arevalo-Herrera M, Binka F, Chitnis C, Collins F, Doumbo OK, Greenwood B, Hall BF, Levine MM, Mendis K, Newman RD, Plowe CV, Rodriguez MH, Sinden R, Slutsker $L$, Tanner M: A research agenda to underpin malaria eradication. PLoS Med 2010, 8:e1000406.

39. Snow RW, Marsh K: The consequences of reducing transmission of Plasmodium falciparum in Africa. Adv Parasitol 2002, 52:235-264.

40. Smith DL, Guerra CA, Snow RW, Hay SI: Standardizing estimates of the Plasmodium falciparum parasite rate. Malar J 2007, 6:131.

41. Smith T, Maire N, Ross A, Penny M, Chitnis N, Schapira A, Studer A, Genton B, Lengeler C, Tediosi F, de Savigny D, Tanner M: Towards a comprehensive simulation model of malaria epidemiology and control. Parasitology 2008, 135:1507-1516.

42. Alonso PL, Atta HY, Drakeley C, Eisele T, Hay SI, Lupez MH, Meek S, Steketee $R$, Slutsker $L$ : A research agenda for malaria eradication: monitoring, evaluation, and surveillance. PLoS Med 2010, 8:e1000400.

doi:10.1186/1475-2875-11-160

Cite this article as: Raso et al:: Mapping malaria risk among children in Côte d'Ivoire using Bayesian geo-statistical models. Malaria Journal 2012 $11: 160$.

\section{Submit your next manuscript to BioMed Central and take full advantage of:}

- Convenient online submission

- Thorough peer review

- No space constraints or color figure charges

- Immediate publication on acceptance

- Inclusion in PubMed, CAS, Scopus and Google Scholar

- Research which is freely available for redistribution 